\title{
ABSTRACTS OF PAPERS PRESENTED AT THE ANNUAL MEETING, CANADIAN ANAESTHETISTS' SOCIETY, JUNE 13-17, 1981
}

Postoperative Hypertension in Coronary Artery Surgery: Influence of the Anaesthetic Agents. William Macllvaine, Marcel Boulanger, Bernard Paiement, Jean-Guy Maille and Jean Taillefer. Institut de Cardiologie de Montreal, 5000 Est rue Belanger, Montreal, Canada HIT IC8.

Hypertension following coronary surgery is generally reported at an alarmingly high incidence ( $35-40$ per cent).

A vigilant program carried out in 1977 at Montreal Heart Institute disclosed a low incidence of 3.5 per cent in 200 consecutive unselected cases. A similar programme in 1980 based on 100 patients showed an incidence of 23 per cent. This highly significant difference is felt to be related to the different anaesthetic management that has occurred since 1977 . Anaesthesia for all the 200 patients was primarily morphine $1.0-1.5$ $\mathrm{mg} \cdot \mathrm{kg}^{-1}$

The 1980 group when divided according to the main anaesthetic agent used, with 40 patients in each group, yields the following incidence of postoperative hypertension:

$\begin{array}{lr}\text { Morphine } & 4 \text { per cent } \\ \text { Fentanyl } & 20 \text { per cent } \\ \text { Halogenated Agents } & 37.5 \text { per cent }\end{array}$

We conclude that early return of sympathetic activity is likely to increase the incidence of post-operative hypertension following coronary artery surgery; hence, early awakening following this type of surgery is not in the best interest of the patient.

Continuous Mixed Venous Oxygen Saturation in Adults With Cardiovascular Disease. K.W. Turnbull, J. Allison, W.A. Dodds, L.C. Jenkins, G.F.O. Tyers and B. Walmsley. Vancouver General Hospital, 855 West 12th Avenue, Vancouver, Canada V5Z 1 M9.

Mixed venous oxygen saturation was monitored continuously in 20 patients. Changes in mixed venous oxygen saturation provided a warning of impending changes in traditionally measured cardiovascular parameters. Changes in heart rate, blood pressure, cardiac output, pulmonary capillary wedge pressure and the derived parameters from haemodynamic tracking (e.g., cardiac index, stroke-volume index, systemic vascular resistance) are pre-empted by changes in mixed venous oxygen saturation. The use of a new pulmonary artery catheter equipped with optical fibres capable of continuous monitoring of the mixed venous oxygen saturation has added an exciting dimension to the care of patients with labile haemodynamic states in the operating room and the surgical intensive care unit.

Critical changes in cardiac output, tissue perfusion and oxygen delivery to the body cell mass are initially reflected in a change exceeding $10-15$ per cent in mixed venous oxygen saturation. This information has replaced cardiac output measurement and haemodynamic tracing as guides for clinical intervention. Clinicians can intervene quickly and correct hypovolaemia, cardiac failure, falling cardiac output and prevent hypotension before progression to impaired oxygenation can occur. Decreases of 10-15 per cent in mixed venous oxygen saturation have occurred with shivering, suctioning, chest physiotherapy and positioning of patients. Modifications of these situations will prevent such changes.

Continuous monitoring of the oxygen transport system with this type of catheter can result in improved patient care.

Effects of Calcium on the Coronary and Systemic Circulation in Patients After Coronary Surgery. E. Moffitt, D. Sethna, R, Gray, J, Bussell, C. Conklin and J. Matloff. Sir Charles Tupper Medical Building. Dalhousie University, University Avenue, Halifax, Nova Scotia, Canada B3H $4 \mathrm{H7}$.

$\mathrm{CaCl}_{2}$ is used commonly in cardiac anaesthesia and in cardiopulmonary resuscitation to increase inotropy, cardiac output and blood pressure. Is this good or bad for the heart? There are varied reports of its actions on the systemic circulation and none of the effects on the coronary bed and coronary flow. We studied both these circulations, before and after administration of one gram of $\mathrm{CaCl}_{2}$, in nine patients early after coronary vein grafting, as part of a larger study, from the premedicated state through anaesthesia and for 24 hours afterward.

Method: A radial artery needle and two thermodilution catheters (pulmonary artery (PA) and coronary sinus (CS)) were placed through the right internal jugular vein, under premedication. We measured serially: cardiac output, total coronary sinus flow (which approximates left coronary flow), arterial and central pressures and A-CS differences of oxygen and lactate.

Nine patients $(5 F, 4 M)$ averaging 60.3 years and $68.2 \mathrm{~kg}$ received a mean of 3.3 vein grafts. NYHA classes were II-4, III-3, and IV-2. Five had morphine (1 $\left.\mathrm{mg} \cdot \mathrm{kg}^{-1}\right)$ anaesthesia with oxygen and four, halothane-oxygen. Mean times were anaesthesia 298, pump 123 and clamp 72 minutes.

After a mean of three hours in the ICU, the calcium study was done, with a mean patient temperature $35.3^{\circ} \mathrm{C}$ and all patients being ventilated. Following a control series, one gram of $\mathrm{CaCl}_{2}$ (mean $14.6 \mathrm{mg} \cdot \mathrm{kg}^{-1}$ ) was given over 15 minutes. The second series was at the end of calcium administration and the third, 10 minutes after injection.

Results: Significant increases at end-injection and 10 minutes later occurred in C.I. (14 per cent), stroke volume ( 14 per cent) and arterial pressure ( 18 per cent). Stroke work nearly doubled $(+90$ per cent). Mean PA pressure went up 18 per cent. All other measurements did not change significantly, including systemic resistance, CS flow, $\mathrm{MVO}_{2}$, arterial and CS lactate levels.

Comment: $\mathrm{CaCl}_{2}, 1 \mathrm{~g}$, given 3 hours postoperatively to patients still hypothermic, increased cardiac output and arterial pressure but did not alter heart rate, RPP or systemic resistance. Stroke work increased greatly but this did not change CS flow or myocardial oxygen or 
lactate consumption significantly. Since RA and wedge pressure did not increase, the changes in output were due to better contractility. $\mathrm{CaCl}_{2}$ improved the systemic circulation without compromising coronary flow or myocardial oxygenation.

TABLE I

EFFECTS OF $\mathrm{CaCl}_{2}$ : I g IN 15 Minutes

\begin{tabular}{lccc}
\multicolumn{4}{c}{ EFFECTS OF $\mathrm{CaCl}_{2}:$ I B IN I5 MiNUTES } \\
\hline HR & Before & End Injection & +10 Min \\
MAP & $78 \pm 14$ & $75 \pm 16$ & $75 \pm 12$ \\
RPP & $77 \pm 6$ & $94 \pm 18^{*}$ & $90 \pm 19 *$ \\
C.I. & $8234 \pm 2.28$ & $10109 \pm 3394$ & $9639 \pm 3195$ \\
SVI & $1.76 \pm 0.38$ & $1.99 \pm 0.47$ & $2.01 \pm 0.54^{*}$ \\
SWI & $23.6 \pm 6$ & $27 \pm 6^{* *}$ & $27 \pm 6^{* *}$ \\
RAP & $21.1 \pm 10$ & $40 \pm 13^{*}$ & $37 \pm 11$ \\
MPAP & $10 \pm 2$ & $10 \pm 2$ & $10 \pm 1$ \\
PWP & $17 \pm 4$ & $21 \pm 4$ & $20 \pm 4^{*}$ \\
SVR & $11 \pm 2$ & $12 \pm 3$ & $12 \pm 2$ \\
PVR & $1191 \pm 902$ & $2155 \pm 1059$ & $1873 \pm 829$ \\
Cor VR & $505 \pm 297$ & $555 \pm 391$ & $525 \pm 431$ \\
CS Flow & $0.94 \pm 0.07$ & $1.22 \pm 0.1$ & $1.19 \pm 0.09$ \\
CSO & $88 \pm 34$ & $95 \pm 46$ & $90 \pm 45$ \\
MVO & $5.9 \pm 1.3$ & $5.5 \pm 1.3$ & $5.6 \pm 1.3$ \\
Art. Lact. & $6.5 \pm 2.2$ & $7.2 \pm 3.7$ & $6.3 \pm 2.4$ \\
CS Lact. & $2.5 \pm 0.8$ & $2.6 \pm 0.9$ & $2.5 \pm 0.9$ \\
\hline
\end{tabular}

$$
n-9 . m \pm \text { S.D. }
$$$$
\begin{aligned}
& n<0.01 \\
& * p<0.02
\end{aligned}
$$

Myxoedema and Open Heart Surgery: Anaesthesia and Intensive Care Unit Experience. D.C. Finlayson and J.A. Kaplan. Department of Anaesthesia, Emory University Hospital, 1364 Clifton Road, N.E., Atlanta, Georgia, 30322 U.S.A.

Myxoedema is associated with depressed cellular function causing: (1) failure of thermoregulation and prolonged depression of all central nervous system (CNS) functions; (2) metabolic disorders such as hyponatraemia and hypoglycaemia; and (3) impaired cardiovascular function further depressed by anaesthesia. These risks are even greater when myxoedema is combined with coronary (CAD) or valvular heart disease. In a recent study of six patients with CAD who underwent coronary artery bypass grafting, five received thyroid preoperatively and again beginning cautiously on the first postoperative day. Two of these awaiting operation died suddenly while taking thyroid. This abstract describes a group whose thyroid was withheld preoperatively and begun aggressively during or immediately after operation.

Patients: Thyroid ablation to produce myxoedema and thus to control angina was carried out on $\mathbf{2 0 0}$ patients, seven of whom (Group I) were later judged suitable for coronary bypass. Five others (Group II) with CAD or aortic stenosis and pre-existing thyroid disease had thyroxin withheld preoperatively to control angina. Hypothyroidism was confirmed by laboratory studies in all but three. The 10 men and two women had a mean age of 59.3 years. One had an aortic valve replacement and a second an aortic valve replacement and coronary bypass. Of 10 coronary bypass patients, six had ejection fractions 50 per cent and two of these six were in congestive heart failure preoperatively. All received propranolol, nitrates and, in four, digoxin, up to the time of operation.

Anaesthesia: Monitoring consisted of electrocardiogram (ECG) leads II and $V_{5}$, radial artery can- nula, a pulmonary artery catheter in seven and central venous pressure (CVP) in five supplemented in this group by left atrial pressure in two. Premedication consisted of reduced doses of morphine and scopolamine supplemented by diazepam in seven. Anaesthesia was induced with diazepam and narcotics accompanied in four cases by Innovar ${ }^{\text {as }}$. Diazepam and narcotics in generally reduced doses combined with a relaxant and nitrous oxide were used for maintenance. A bubble oxygenator was used with a crystalloid prime. Perioperative haemodynamic studies were done (Table I). Digoxin was given to those who were not digitalized. All received steroids. L-thyroxine was given at the end of bypass or immediately on admission to the ICU, except in one patient whose thyroxine was withheld for several days due to ventricular ectopy and who developed severe hyponatraemia in the absence of steroids when it was restarted. The mean total dose was $108 \mu \mathrm{g}$. One patient required infusions of glucose-insulin, inotropes, vasodilators, and the intra-aortic balloon pump to terminate bypass. Another patient required a dopamine infusion. Four others required vasodilators to control hypertension in the early postoperative period. All survived.

Conclusions: The experience of these 12 patients suggests that (1) preoperative thyroid supplementation is unnecessary, (2) aggressive replacement can begin after operation and should be accompanied by steroids and (3) with adequate monitoring and care, ordinary approaches to anaesthesia are possible with good results.

TABLE I

Mean Values

\begin{tabular}{lccc}
\hline & Pre-induction & Pre-CPB & Posi CPB \\
\hline Cl & 1.91 & 1.82 & 2.24 \\
SI & 27.9 & 24.7 & 28 \\
PVR & 132.7 & 136.7 & 123 \\
SVR & 1916 & 2174 & 1547 \\
RVSWl & 3.93 & 3.58 & 3.25 \\
LVSWl & 31.54 & 28.49 & 30.68 \\
\hline
\end{tabular}

C - Cardiac Index: SI - Stroke Index. PVR - pulmonary vascular resistance. SVR - systemic vascular resistance. RVSWI - right ventricular stroke work index. LVSWI - left ventricular stroke work index.

The Effect of Barbiturate Anaesthesia on the Facilitated Absorption of Cerebrospinal Fluid. Charles E. Hope and James $A$. Love. Department of Anaesthesia, Dalhousie University, Halifax, N.S.

Barbiturates have been studied extensively in the management of increased intracranial pressure (ICP). Recent reports suggest that the resistance to cerebrospinal fluid (CSF) absorption is not constant and that it may decrease at CSF pressures greater than $25 \mathrm{~mm} \mathrm{Hg} .{ }^{1,2}$ As these studies were conducted in animals under barbiturate anaesthesia it appeared relevant to determine whether or not the demonstrated facilitated absorption of CSF was in any way dependent on the anaesthetic.

Method: Cats were paralyzed with gallamine triethiodide ( $5 \mathrm{mg} \cdot \mathrm{kg}^{-1}$ ) their tracheae were intubated immediately and they were ventilated with nitrous oxide 70 per cent and oxygen 30 per cent. Bupivicaine 0.5 per cent in rheomacrodex 10 per cent was used for regional block of all surgical sites. The external auditory meati were packed with pledgets soaked with bupivacaine 0.5 
per cent before placing the cats in a stereotactic frame. Arterial and central venous catheters were placed by the femoral route; an infusion cannula was placed in the cisterna magna. ICP, BP and CVP were recorded continuously. Blood gases and body temperature were normal throughout. After a control period, artificial CSF was infused using a constant infusion rate technique.' Following a period of recovery, pentobarbitone sodium $30 \mathrm{mg} \cdot \mathrm{kg}^{-1}$ was administered and the study was repeated.

Results: The results of the present study together with those obtained previously' are shown in the following table.

Observations: The time course of the changes in ICP during the infusion is qualitatively similar under barbiturate anaesthesia. ${ }^{1} \mathrm{~N}_{2} \mathrm{O}-\mathrm{O}_{2}$ anaesthesia and $\mathrm{N}_{2} \mathrm{O}-$ $\mathrm{O}_{2}+$ barbiturate anaesthesia. Under both barbiturate anaesthesia' and $\mathrm{N}_{2} \mathrm{O}-\mathrm{O}_{2}$ +barbiturate anaesthesia, the resistances to CSF absorption before and after facilitation are similar. With $\mathrm{N}_{2} \mathrm{O}-\mathrm{O}_{2}$ anaesthesia, the resistances to CSF absorption are higher than those obtained with barbiturates.

Conclusion: The facilitation of CSF absorption is not dependent on the barbiturate anaesthesia. However, the addition of barbiturate to the anaesthetic augments the absorption of CSF in the model as described.

TABLE I

anaesthesia Resistance to CSF absorption $\mathrm{mmHg} / \mathrm{ml} \cdot \mathrm{min}$ '

\begin{tabular}{lcc}
\hline \hline & $\begin{array}{c}\text { Before } \\
\text { Facilitation }\end{array}$ & $\begin{array}{c}\text { After } \\
\text { Facilitation }\end{array}$ \\
\hline $\mathrm{N}_{2} \mathrm{O}-\mathrm{O}_{2}$ & 145 & 105 \\
$\mathrm{~N}_{2} \mathrm{O}-\mathrm{O}_{2}+$ Barbituratc & 120 & 74 \\
Barbiturate & 127 & 63 \\
\hline
\end{tabular}

\section{REFERENCES}

I. Love, J.A. \& LesLie, R.A. Changes in resistance to cerebrospinal fluid absorption during prolonged infusion studies. In: Shulman, K., et al. (Eds.), Intracranial Pressure IV, pages 451-455. SpringerVerlag, Berlin (1980).

2. Chandler, W.F., Zwetnow, N.N. \& Lofgren, J. Hysteresis in the relationship between cerebrospinal fluid absorption minus formation and cerebrospinal fluid pressure in the dog. Neurosurgery 5, 349-353 (1979).

Homocystine Excretion Related to Nitrous Oxide Anaesthesia. J.C. Bevan, D.S. Rosenblatt, C.L. Clow and $V . A$. Chapman. Department of Anaesthesia, Montreal Children's Hospital, 2300 Tupper Street, Montreal, Canada H3H 1 P3.

Prolonged exposure to nitrous oxide $\left(\mathrm{N}_{2} \mathrm{O}\right)$ in some patients leads to bone marrow depression and megaloblastic changes suggestive of vitamin $B_{12}$ deficiency. The postoperative administration of 50 per cent $\mathrm{N}_{2} \mathrm{O}$ has also been associated with the development of megaloblastic haemopoiesis within 5-24 hr. ${ }^{2}$ Rat experimentation has confirmed the toxicity of $\mathrm{N}_{2} \mathrm{O}$ and demonstrated that the cellular damage in the marrow and blood is dose and time related. ${ }^{3}$ There is, therefore. concern that the current use of $\mathrm{N}_{2} \mathrm{O}$ in most general anaesthetic techniqes may be undesirable.

In mammals the enzymes methionine synthetase and methylmalonyl $\mathrm{CoA}$ mutase are known to be vitamin $B_{12}$ dependent. Brief exposure of $30 \mathrm{~min}$ to 50 per cent $\mathrm{N}_{2} \mathrm{O}$ decreases methionine synthetase activity in rats by two thirds and it is inactivated after $6 \mathrm{hr} .^{4}$ Further indication of disturbed vitamin $B_{12}$ metabolism is an abnormal deoxyuridine suppression test which develops shortly after. However, methylmalonyl $\mathrm{CoA}$ mutase activity, as determined by methylmalonic acid excretion, appears to be unaffected by $\mathrm{N}_{2} \mathrm{O}$. If the same is true in man, then the inactivation of methionine synthetase would block the conversion of homocystine to methionine, and homocystine would be excreted in the urine.

At present bone marrow examination is necessary to show the megaloblastic changes caused by $\mathrm{N}_{2} \mathrm{O}$. Although there are no comparable data available on homocystine excretion in rats it was hoped that the detection of the abnormal metabolite in the urine could be an equally reliable indicator of disturbed vitamin $B_{12}$ metabolism. This would then offer a simple screening test for $\mathrm{N}_{2} \mathrm{O}$ toxicity for clinical use.

We studied 41 surgical patients thought to be at risk. These included 17 neonates (mean age 11.2 days, range $12 \mathrm{hr}-4 \mathrm{wk}$ ) exposed to $50-66$ per cent $\mathrm{N}_{2} \mathrm{O}$ for a mean of $3.0 \mathrm{hr}$ (range $1-6.5 \mathrm{hr}$ ), and 24 older children and young adults (mean age $8.9 \mathrm{yr}$, range $6 \mathrm{wk}-23 \mathrm{yr}$ ) having longer exposures to 66 per cent $\mathrm{N}_{2} \mathrm{O}$ for a mean of $7.2 \mathrm{hr}$ (range $2-18 \mathrm{hr}$ ). The first urine voided postoperatively was tested for the presence of homocystine. This is detected with nitroprusside which reacts chemically with the urinary disulphides cystine and homocystine, following their reduction to sulphydryl compounds by cyanide. Positive reactions are found if the sample contains more than $10 \mathrm{mg} \cdot \mathrm{dl}^{-1}$ cystine or $5 \mathrm{mg} \cdot \mathrm{dl}^{-1}$ homocystine. Any questionable result was checked on an amino acid analyser. The results were all negative for homocystine. However. the failure to demonstrate homocystine excretion in any of these patients cannot exclude the possibility of any disturbance in vitamin $\mathrm{B}_{12}$ metabolism by $\mathrm{N}_{2} \mathrm{O}$ anaesthesia. It is possible that methionine synthetase will be affected some time before homocystine appears in the urine. Testing of patients having even longer exposures to $\mathrm{N}_{2} \mathrm{O}$ may, therefore, result in positive findings.

\section{REFERENCES}

1. Lassen, H.C.A., Henriksen, E., Neukirch, F. \& KRISTENSEN, H.S. Treatment of tetanus: entire bone-marrow depression after prolonged nitrousoxide anaesthesia. Lancet $1,527-530$ (1956).

2. Amess, J.A.L., Burman, J.F., ReEs, G.M., NanCEKIEVILl, D.G., \& Mollin, D.L. Megaloblastic haemopoiesis in patients receiving nitrous oxide. Lancet 2, 339-342 (1978).

3. Kripke, B.J., Talarico, L., Shah, N.K. \& KELMAN, A.D. Hematologic reaction to prolonged exposure to nitrous oxide. Anesthesiology 47, 342348 (1977).

4. Deacon, R., Lumb, M., Perry, J., Chanarin, 1., Minty, B., Halsey, M.J. \& NunN, J.F. Selective inactivation of vitamin $B_{12}$ in rats by nitrous oxide. Lancet 2, 1023-1024 (1978). 
Nitrous Oxide Added to Halothane Depresses Coronary Flow and the Heart in Patients with Coronary Artery Disease. E. Moffitt, J. Bussell, D. Serhna, R. Gray, $M$. Raymond and J. Matloff. Sir Charles Tupper Medical Building, Dalhousie University, University Avenue, Halifax, Nova Scotia B3H $4 \mathrm{H} 7$.

Nitrous oxide and halothane 0.5 per cent do not depress the circulation in normal man but clinically they appear to do so in patients with coronary artery disease. We studied this combination in 13 patients having coronary artery bypass grafts. With steady haemodynamics 15 minutes after tracheal intubation but before incision, 50 per cent nitrous oxide was added to 0.5 per cent halothane-oxygen anaesthesia for 15 minutes. This was part of a larger study from preinduc tion throughout operation. Patients gave informed consent. They averaged 59 years and $78 \mathrm{~kg}$. All were on propranolol and seven had previous myocardial infarcts.

Methods: All patients had an oxygen-halothane induction ( 10 minutes of $1-1.5$ per cent) after thiopentone $(\mathrm{M}-133 \mathrm{mg})$ and tracheal intubation after pancuronium. Five patients were pretreated 45 minutes before induction with intravenous propanolol $0.1 \mathrm{mg} \cdot \mathrm{kg}^{-1}$.

We measured total coronary sinus (CS) blood flow (which approximates left coronary flow), arterial-CS lactate and oxygen differences, cardiac output, radial and central pressures. Two thermodilution catheters (PA and CS) and a radial needle were placed under premedication (secobarbitone) before anaesthesia.

Results: (Table I): Significant depression of heart rate, arterial pressure ( 35 per cent), RPP, and cardiac index ( 18 per cent) occurred, with a severe fall in stroke work ( 35 per cent). Systemic vascular resistance fell, but not pulmonary or coronary resistance. CS flow fell 36 per cent and $\mathrm{MVO}_{2} 38$ percent. CS lactate increased, with myocardial extraction almost reaching a production pattern. On nitrous oxide mean $\mathrm{Pa}_{0,}$ fell from 348 to $168 \mathrm{~mm} \mathrm{Hg}, \mathrm{Pa}_{\mathrm{CO}_{2}}$ from 39 to $36 \mathrm{~mm} \mathrm{Hg}$, while $\left[\mathrm{H}^{+}\right]$ went from 38.02 to $34.67 \mathrm{nmol} / \mathrm{l}$ ( $\mathrm{pH}$ from 7.42 to 7.46 ). There were no differences due to propranolol pretreatment.

Discussion: Fifty per cent nitrous oxide for 15 minutes, added to 0.5 per cent halothane in patients for coronary artery bypass grafts caused major depression. Stroke work, MAP, CS flow all fell severely and proportionately: evidence of deeper anaesthesia and a

\begin{tabular}{|c|c|c|c|}
\hline & $\begin{array}{c}\text { Before } \\
\mathrm{N}_{2} \mathrm{O}\end{array}$ & $\begin{array}{c}15 \mathrm{Min} \\
\mathrm{N}_{2} \mathrm{O}\end{array}$ & $\mathbf{P}$ \\
\hline HR & $72 \pm 13$ & $64 \pm 9$ & 0.003 \\
\hline MAP & $101 \pm 16$ & $64 \pm 15$ & 0.002 \\
\hline RPP & $10373 \pm 2484$ & $6650 \pm 1694$ & 0.002 \\
\hline $\mathrm{CI}$ & $2.84 \pm 0.5$ & $2.03 \pm 0.4$ & 0.003 \\
\hline SVI & $34.9 \pm 7$ & $32.1 \pm 5$ & N.S. \\
\hline SWI & $54 \pm 10$ & $35 \pm 10$ & 0.003 \\
\hline SVR & $1671 \pm 552$ & $1412 \pm 481$ & 0.01 \\
\hline PVR & $318 \pm 119$ & $326 \pm 74$ & N.S. \\
\hline CVR & $1.1 \pm 0.5$ & $1.2 \pm 0.5$ & N.S. \\
\hline RAP & $8 \pm 4$ & $8 \pm 3$ & N.S. \\
\hline MPAP & $18 \pm 4$ & $13 \pm 3$ & 0.01 \\
\hline PWP & $16 \pm 3$ & $13 \pm 3$ & N.S. \\
\hline CS Flow & $96 \pm 32$ & $61 \pm 18$ & 0.002 \\
\hline $\mathrm{CSO}_{2}$ & $7 \pm 1.2$ & $6.5 \pm 1.3$ & 0.02 \\
\hline $\mathrm{MVO}_{2}$ & $8.2 \pm 3.3$ & $5.3 \pm 1.9$ & 0.002 \\
\hline Art.Lac. & $1.2 \pm 0.37$ & $1.8 \pm 0.4$ & N.S. \\
\hline C.S.Lac. & $0.85 \pm 0.21$ & $101 \pm 0.37$ & 0.01 \\
\hline Lac.Ext.\% & $26.6 \pm 12.9$ & $11.2 \pm 32$ & 0.04 \\
\hline
\end{tabular}

trend toward myocardial and circulatory failure. This may be largely a second gas effect: adding nitrous oxide to halothane increases halothane uptake. Myocardial oxygen consumption fell as expected. but CS oxygen content should have risen if oxygen supply was adequate. It fell and the normal lactate extraction went almost to production: evidence of anaerobic metabolism due to inadequate tissue oxygen supply.

Conclusion: Nitrous oxide plus halothane producing hypotension in coronary patients, raises a real risk of myocardial ischaemia and damage.

Reversibility of Diazepam Overdose by Physostigmine in Animals. George Havasi. Jonas Gintautas, Ilona Havasi and Gabor B. Racz. Department of Anesthesiology. Texas Tech University, School of Medicine, P.O. Box 2217 , Lubbock, Texas 79408 U.S.A.

There are reports in the literature suggesting that physostigmine fails to reverse diazepam overdosage. However, our clinical experience indicates quite opposite results. To clarify the nature of drug interaction we decided to evaluate the effects of physostigmine in cats overdosed with diazepam.

Methods: Dose-response curves for diazepan were established in 18 adult cats of either sex. Diazepam (4. $6,8,10$ and $12 \mathrm{mg} \cdot \mathrm{kg}^{-1}$ ) was administered intravenously over two minutes. In the second part of the study animals received physostigmine $0.02 \mathrm{mg} \cdot \mathrm{kg}^{-1}$ intravenously over one minute. Diazepam $(8,10,12$ and $14 \mathrm{mg} \cdot \mathrm{kg}^{-1}$ ) was injected two minutes later. The response of animals to pain and noise stimuli was evaluated 2, 5 and 10 minutes after completion of diazepam injection. Animals had several days to recover between two experiments.

Results: Our results showed clear awakening effect from physostigmine. The diazepam dose-response curve was shifted parallel to the right by physostigmine indicating competitive antagonism. When pain was used as the stimulus physostigmine always shifted the curve to the same distance represented by an intravenous dose of diazepam $2 \mathrm{mg} \cdot \mathrm{kg}^{-1}$. When noise was used for stimulation physostigmine shifted the curve to the same distance each time we evaluated the animals. However, with this stimulus the shift represented a dose of diazepam $4 \mathrm{mg} \cdot \mathrm{kg}^{-1}$.

Although the physostigmine dosage remained the same throughout the study, as the dosage of diazepam increased several cats showed severe cholinergic response after the injection of diazepam. When a large enough dose of diazepam ( $14 \mathrm{mg} \cdot \mathrm{kg}^{-1}$ ) was used all animals became unresponsive even in the presence of physostigmine.

Discussion: Since diazepam has no anticholinergic activity, its reversibility by physostigmine suggests a non-cholinergic mechanism of action. It is known that physostigmine has analeptic activity by stimulating cerebral cholinergic receptors. However this is the first study indicating competitive antagonism between the two drugs. This competitive antagonism has not been found in studies on purified diazepam receptors. This antagonistic effect could be achieved from a dose of physostigmine which does not induce peripheral cholinergic reaction. Our finding that large doses of diazepam potentiate the cholinergic action of physostigmine was unexpected.

When the largest dose of diazepam had been used. 
physostigmine $0.02 \mathrm{mg} \cdot \mathrm{kg}^{-1}$ did not induce an adequate antagonistic effect and all animals were unresponsive. In similar clinical circumstances the dosage of physostigmine should be increased very carefully and discontinued at the first sign of peripheral cholinergic reaction, otherwise severe cholinergic complications could develop.

The use of Transcutaneous Oxygen Electrodes in the Presence of Anaesthetic Agents. Kenneth Sugioka and Charles Woodley. Department of Anesthesiology, University of North Carolina School of Medicine, Chapel Hill, North Carolina, 27514 U.S.A.

In 1971 Severinghaus reported on errors due to the presence of halothane in blood when oxygen measurements were made. In $1979 \mathrm{McHugh}$ found that halothane affected oxygen measurements performed with oxygen microelectrodes. No study has been published on the effects of all commonly used anaesthetics on oxygen measurements using transcutaneous $\mathrm{Po}_{2}$ electrodes. In vitro studies using nitrous oxide, halothane, enflurane and isoflurane, were done using a transcutaneous oxygen analyzer equipped with special membranes.*

The instrument was zeroed on 100 per cent nitrogen and 20 per cent oxygen with 80 per cent nitrogen or 100 per cent oxygen were used to determine the basic drift and to establish one of the oxygen concentrations as a carrier gas for the anaesthetic agents. Two types of membranes, polypropylene or teflon, werc used with the oxygen transducer. Each of the gases at two different concentrations in one of the two oxygen mixtures (nitrous oxide excepted) was humidified and passed through a cuvette containing the transducer. Data were recorded every 10 minutes during the 60 minutes required for each experiment. The data were analyzed at the 30 and 60 minute periods for mean drift and standard error of the mean comparing teflon and polypropylene membranes. "P" values were derived for each set of experiments.

The results would seem to indicate that:

(1) There was significantly less drift with either 20 per cent or 100 per cent oxygen in the absence of any anaesthetic agent when the teflon membrane was used.

(2) In the presence of nitrous oxide, enflurane, and isoflurane, the teflon membrane showed greater stability than the polypropylene but the amount of drift with either membrane in the presence of these agents was acceptable.

(3) With halothane, a significantly large drift occurred using membranes other than teflon, at two different anaesthetic concentrations, regardless of the oxygen mixtures used as the carrier gas.

The conclusion derived from this study is that teflon membranes should be used when the transcutaneous oxygen analyzer is used in the presence of halothane. Further, that although the response time is somewhat lengthened by the use of teflon membranes, the stability that can be achieved in contrast to other membrane materials makes it the logical choice for use in transcutaneous oxygen analyzers. WI).

*Sensomatt III (Biochem, International, Milwaukee.
Double Blind Single Dose Study to Compare the Postoperative Analgesic Effects of Preoperative Zomepirac and Codeine in Short Stay Patients. G.L. Dunn, D.H. Morison, A. Fargas-Babjak and D.P. Brodie. Department of Anaesthesia, McMaster University, Hamilton, Ontario L8N $3 Z 5$.

Zomepirac sodium is a new non-narcotic analgesic which has previously been assessed in both the postoperative and chronic pain models. Initial trials indicate that it is superior to parenteral morphine $8 \mathrm{mg}$ in the control of postoperative pain.

The objective of the present study was to compare the efficacy of zomepirac $100 \mathrm{mg}$ and codeine $60 \mathrm{mg}$. when given as oral premedications, in terms of control of postoperative pain and incidence of side effects, in patients scheduled for short stay surgery.

Merhods: Institutional approval of the protocol was obtained. and all patients gave an informed written consent. Patients presenting for laparoscopic sterilization by fallope ring or surgical removal of impacted third molars were studied, since these usually result in moderate to severe postoperative pain. Patients were stratified by surgical procedure and randomized within strata to the two premedication regimes - Zomepirac $100 \mathrm{mg}$ or codeine $60 \mathrm{mg}$. All patients were A.S.A. I, aged 18 to 45 years, and weighed 45 to $90 \mathrm{~kg}$. Of the 88 patients studied, 48 underwent laparoscopic sterilization, and 40 surgical removal of impacted third molars. of these 24 and 20 , respectively, received each premedication regime. Patients were premedicated orally 30 minutes before operation. Blindness was ensured by the use of medication capsules of identical appearance, and labelled by number only.

Measurements included pain intensity by visual analogue and verbal ordinal scales, both administered by one nurse observer. Assessments were made, preoperatively for practice, and postoperatively at $1 \frac{1}{2}, 2,3$, 4,5 , and 6 hours from the time of premedication. In addition, vital signs were recorded, and the incidence of postoperative side effects was solicited. A standard anaesthetic technique was used which avoided analgesic and local anaesthetic supplementation. Postoperatively, patients were allowed additional analgesia on request, but a standardized regime was employed, and the time of remedication was recorded. Recovery times and "street fitness" times were assessed using standardized criteria.

Statistical Analysis: Remedication times were analyzed using a survival model with patient and procedural variables included as covariates, and pain scores by analysis of variance.

Results: Within procedural strata, age, weight, and height of patients were similar between the two premedication groups. Procedural variables were comparable, and premedication to induction time, recovery time, and "street fitness" time did not differ significantly between premedication groups.

In the dental patients, Zomepirac was significantly superior to codeine in terms of remedication times $(\mathrm{p}=$ 0.013 ). At six hours after premedication, only six patients receiving Zomepirac had required additional analgesia compared to 15 for codeine. Mean pain levels were considerably lower at all observation points for the Zomepirac group even though the codeine group had required significantly more additional analgesia.

In the laparoscopic group, the remedication time 
profile was similar between treatments, and mean pain levels were also comparable.

The incidence of postoperative vomiting was similar for both premedications. In the dental group, one Zomepirac patient vomited compared to none in the codeine group. In the laparoscopic group, 8 Zomepirac patients ( 33 per cent) vomited compared to $6(25$ per cent) in the codeine group. There were no clinically significant differences in vital signs between premedication.

Conclusion: Zomepirac $100 \mathrm{mg}$ was an effective oral analgesic premedication in the dental patients, and was significantly superior to codeine $60 \mathrm{mg}$. In the laparoscopic group, neither premedication was satisfactory, and investigation of alternative premedication regimes is indicated.

Acknowledgement: This study was supported by a grant-in-aid from McNeil Laboratories (Canada) Limited.

A Double Blind Comparison of Etomidate and Alfathesin in Out-Patient Surgery. D.H. Morison, G.L. Dunn, and A. deGraft Johnson. Department of Anaesthesia, McMaster University, Hamilton, Ontario L8N 325.

Etomidate is a short-acting non-barbiturate intravenous anaesthetic. The purpose of this study was to compare etomidate and alfathesin in terms of clinical efficacy, cardiorespiratory changes, side effects, and recovery characteristics when used for induction and maintenance of anaesthesia in patients undergoing out-patient surgery.

Methods: Institutional approval of the protocol was obtained and all patients gave informed written consent. Forty-eight females, A.S.A. I, aged $16-40$ years, weighing between $45-90 \mathrm{~kg}$ and scheduled for minor gynaecological surgery were studied. Patients were assigned randomly to one of two anaesthetic techniques. No premedication was used and all patients received fentanyl $\mathbf{l} \mu \mathrm{g} \cdot \mathrm{kg}^{-1}$ intravenously one minute prior to induction. Group I (24 patients) was induced with etomidate $0.3 \mathrm{mg} \cdot \mathrm{kg}^{-1}$ and Group II (24 patients) with alfathesin $75 \mu \mathrm{l} \cdot \mathrm{kg}^{-1}$ injected intravenously over 45 seconds. Maintenance was with 70 per cent nitrous oxide with oxygen and increments equal to 25 per cent of the induction dose were injected if indicated on clinical grounds. An experienced anaesthetist not involved in the administration of the anaesthetic acted as observer. "Blindness" of the observer was achieved by pre-dilution of alfathesin to be equivolumetric and of identical appearance with etomidate.

Systolic and diastolic blood pressures, pulse rate (Dinamap 845 recorder), minute volume and respiratory rate (Wright's electronic respirometer) were recorded preoperatively and every mintue during anaesthesia. All side effects were recorded using a standardized scoring system. Recovery and "street fitness" times were noted and postoperative side effects were documented by direct observation and by the use of patient questionnaires.

Results: The two groups were similar with respect to age, weight, and duration of procedure. Systolic and diastolic blood pressures showed little change in either group but with etomidate there was a tendency for a slight elevation and with alfathesin for a small decrease. The pulse rate increased initially in both groups (etomi- date by 14 per cent and alfathesin by 18 per cent). This increase was maintained with alfathesin but with etomidate the pulse rate decreased to below preoperative levels. Minute volume fell initially by 40 per cent with alfathesin and returned to the preoperative level by five minutes. The minute volume changes with etomidate followed a similar pattern but with a smaller initial decrease and then rose to above preoperative levels. The respiratory rate increased equally in both groups. Apnoea occurred in nine patients ( 38 per cent) following alfathesin compared to five patients ( 21 per cent) after etomidate, but this difference is not statistically significant $(p=0.34)$. The mean duration of apnoea was 19.9 seconds with alfathesin and 42.4 seconds with etomidate $(p=0.03)$. Recovery and "street fitness" times were similar in both groups. Pain upon injection was not noted with alfathesin but occurred in 10 (42 per cent) of the etomidate group, which was a highly significant difference $(p=0.0006)$. Pain was more likely to occur if a hand vein was used (8/14 or 57 per cent) compared to an arm vein ( $2 / 10$ or 20 per cent) but this is not a significant difference $(p=0.1)$. Involuntary movements occurred in $12 / 24$ ( 50 per cent) of the etomidate group compared to $6 / 24$ (25 per cent) for alfathesin $(p=0.07)$. Minor respiratory upsets including hiccoughs, coughing and minor laryngospasm occurred with similar frequency in each group. Postoperative vomiting occurred in nine patients ( 38 per cent) of the etomidate group compared to only two ( 8 per cent) of the alfathesin group $(p=0.036)$. Patients rated the quality of induction with alfathesin higher than that with etomidate.

Conclusion: Etomidate, used under the conditions of this study, produced less cardiorespiratory changes than alfathesin but was associated with a higher incidence of side effects such as pain on injection, involuntary movements, and postoperative vomiting.

Acknowledgement: This study was funded by a grant-in-aid from McNeil Laboratories (Canada) Limited.

Thiopentone Versus Midazolam for Induction of Anaesthesia: Influence of Diazepam Premedication. Brendan T. Finucane. Department of Anesthesia, Grady Memorial Hospital, 80 Butler Street, S.E., Atlanta, GA., 30303 U.S.A.

Forty-eight healthy patients undergoing routine surgery participated in this double-blind parallel study in which thiopentone sodium and midazolam maleate were compared for induction of anaesthesia. Twelve patients in each group received diazepam premedication. The purpose of this study was four-fold. First, to compare the efficacy of these two medications as induction agents using fixed criteria; second to find the optimal dose of midazolam for induction; third to evaluate the effects of diazepam premedication on the induction dose of both medications and, finally, to record and compare the incidence of venous thrombosis resulting from the use of these two medications.

The results showed that adequate induction of anaesthesia was achieved using 0.28 milligrams per kilogram of midazolam and 3.5 milligrams per kilogram of thiopentone. These doses were not altered by preoperative medication with diazepam. The recovery time was significantly prolonged in those patients who 
had received midazolam. The shortest recovery time was observed in those patients who had received thiopentone with diazepam. There were four cases of phlebitis in the thiopentone group and two in the midazolam group.

In conclusion, midazolam maleate, which is a water soluble benzodiazepine, provided satisfactory induction of anaesthesia at a dose of $\mathbf{0 . 2 8}$ milligram per kilogram. However recovery time was significantly prolonged in those patients who had received midazolam.

Comparison of Midazolam and Thiopentone as Induction Agents for General Anaesthesia. J.R. Maltby and R.C. Hamilton. Department of Anaesthesia, Foothills Hospital, 140329 th Street, N.W., Calgary, Alberta.

Midazolam is a water-soluble benzodiazepine which has been used as an induction agent in the U.S.A. and Great Britain. The U.S. reports have been favorable, the British ones less so because midazolam had the same variability of effect as other benzodiazepines.

The initial part of our clinical study was a doseranging trial of midazolam $(0.1,0.15,0.20$, and 0.25 $\mathrm{mg} \cdot \mathrm{kg}^{-1}$ ) in 40 fit young ladies undergoing therapeutic abortions on a day-care basis. The two lower doses gave sedation and occasionally sleep. The two higher doses induced sleep in more than 80 per cent of patients. The highest dose $0.25 \mathrm{mg} \cdot \mathrm{kg}^{-1}$ was then used for a randomised comparison with thiopentone 6 $\mathrm{mg} \cdot \mathrm{kg}^{-1}$. No premedication was used and the only other agents were nitrous oxide and intermittent supplements of the induction agent.

Thirty patients have been studied in the comparative trial. Midazolam gives smooth induction with virtually no side-effects but not all patients were completely asleep with $0.25 \mathrm{mg} \cdot \mathrm{kg}^{-1}$ or even with a supplementary $0.08 \mathrm{mg} \cdot \mathrm{kg}^{-1}$ and onset of sleep was slower and more gradual (often 2 minutes) than with thiopentone. However there was no pain on injection, even in small veins, and only two cases of thrombosis in the 55 patients who have received midazolam. It may therefore be a useful alternative to diazepam as an intravenous sedative and merits study in that field of use.

The final 30 patients in our trial will all receive fentanyl $1 \mu \mathrm{g} \cdot \mathrm{kg}^{-1}$ as intravenous premedication 30 seconds before the induction agent to see if this will allow Midazolam to be used as an induction agent and to give better surgical conditions.

Airway Dimensions in Children With and Without Cleft Palate. G.A. Morgan and D.J. Steward. Department of Anaesthesia, The Hospital for Sick Children, 555 University Avenue, Toronto, Ontario M5G IX8.

Our experience with pre-cut, pre-shaped tracheal tubes during anaesthesia for cleft palate surgery in children has caused concern in two areas.

1. Lack of precise knowledge of the internal dimensions of the normal airway in children of various ages may result in the design of tracheal tubes which are liable to endobronchial placement during anaesthesia.

2 . That children with diseases requiring oropharyngeal surgery, e.g. for repair of cleft palate, are of a smaller size overall than their unaffected peers and this may also include their airway dimensions.
We have studied soft tissue X-Rays of the head and neck to compare upper airway dimensions of two groups of children between the ages four and eighteen years. The first group (A), comprised children treated surgically for cleft palate. The second (B), comprised children undergoing minor orthodontic procedures over a period of years. In a separate study. also to be reported, we have measured the length of the trachea during elective bronchoscopy in children of various ages. Specific dimensions examined in the two studies were:

i. Submentum to anterior margin lower lip;

ii. Anterior margin lips to incisor teeth;

iii. Anterior margin lips to anterior border $\mathrm{C} 2 \mathrm{ver}$ tebra;

iv. Anterior border $\mathrm{C} 2$ to vocal cords;

$v$. Vocal cords to carina;

vi. Level of vocal cords relative to nearest cervical vertebra;

vii. Angles describing changes in the path of the airway.
(a) Chin, between lines $\mathrm{i}$ and iii
(b) Pharyngeal, between lines iii and iv.

We have correlated these measurements with the age, height and weight of the patient at the dates of $\mathrm{X}$-Ray, and have constructed graphs to show the progressive development of the airway dimensions studied between the ages of four and eighteen years. This information is not available in the medical literature at present. Our preliminary results show that normal females, Group (B), were taller than females with cleft palate, in Group (A), at all ages, although there was no difference in the heights of the males.

\section{E.G. Females}

Age 4 Years:

Group (A) Height $-90 \mathrm{~cm}$, Group (B) Height $-94 \mathrm{~cm}$. Age 16 Years:

Group (A) Height $-155 \mathrm{~cm}$, Group (B) Height$165 \mathrm{~cm}$.

Mean Heights only are quoted.

The mean weights of both males and females of Group (B) were greater than those of Group (A) at all ages e.g. Males Age 5 yr Mean Weight Group (A) $15 \mathrm{~kg}$ Group (B) $-21 \mathrm{~kg}$. The normal subjects were larger morphometrically than those with cleft palate with regard to airway measurements i, ii and iv. There was widespread variation in the angles measured, both at the pharynx and between the lines describing dimensions $i$ and iii in Groups (A) and (B), males and females, although there appeared to be some trend towards an increase in both angles with age in all Groups.

We suggest that this information could contribute to the design of an ideal tracheal tube for paediatric use. Such a design will be appended.

Isoflurane for Paediatric Outpatients. D.J. Steward. Department of Anaesthesia, The Hospital for Sick Children, 555 University Avenue, Toronto, Ontario M5G 1 X8.

Isoflurane was administered to a series of paediatric patients aged 3-7 years presenting for minor otological surgery on a day basis. All anaesthetics were administered by the same anaesthetist.

The following parameters were studied: 
1. Speed of induction of anaesthesia to a zero response to surgical stimulation.

2. The incidence of intra-operative complications related to isoflurane.

3. Speed of recovery in the post-anaesthetic room as measured by: (a) A post-anaesthesia recovery scoring system, (b) Tests of co-ordination.

4. The incidence of post-operative complications in the postanaesthetic room.

5. The return to normal status at home and incidence of late complications by means of a parent questionnaire.

The results obtained in the series of children given isoflurane were compared to previous dat a available for patients either given halothane or enflurane.

Results: The speed of induction of anaesthesia with isoflurane was intermediate between that of halothane and that of enflurane. The incidence of intra-operative complications was low. The principal one of coughing and breath-holding occurred in five per cent of patients. The rate of post-operative recovery compared favourably with either halothane or enflurane and the return to a normal status at home was more rapid than with either of the other agents. Late complications were seen less frequently than with halothane or enflurane.

Low Dose Epidural Morphine for Postoperative Analgesia. Cloid D. Green and Pamela J. Masoud. Department of Anesthesiology, Veterans' Administration Medical Center, 4101 Woolworth, Omaha, Nebraska, 68105 U.S.A.

The efficacy of low dosage intrathecal morphine for relief of pain has been previously reported. The dose of morphine required by epidural injection for relief of pain has been reported to be several orders of magnitude greater. A study was devised to test whether low dose epidural morphine provided significantly greater postoperative analgesia than an equal amount of the narcotic by intravenous or intramuscular injection.

Informed consent was obtained from patients scheduled to undergo thoracotomy or major abdominal surgery. The Pharmacy Service of the Medical Center prepared pure morphine sulphate solution, one milligram per five $\mathrm{ml}$ of distilled water. Doses of either $10 \mathrm{or}$ $15 \mathrm{ml}$ were supplied in a double blind manner according to a random number generated code. The first epidural injection was made in the post-anaesthesia recovery room as soon as the patient was awake and a second injection was made twenty-two to twenty-six hours later. All patients were allowed to have additional injections of narcotic on a p.r.n. basis for the control of pain. A total of fifty epidural injections was made. At the completion of the series the code was broken and the charts of the participants analysed for the dose and timing of narcotic injections required in addition to the epidural injection.

The average epidural dose of morphine base was $2.8 \mathrm{mg}$. Those patients who received epidural morphine in the immediate post surgical injection required an average of an additional $12.55 \mathrm{mg}$ of morphine intravenously during the following approximately twentyfour hours. Those who initially received placebo by epidural injection required an average of $21.22 \mathrm{mg}$ of morphine during the same time span. Following the second epidural injection little difference in intra- venous narcotic requirement was found; $5.67 \mathrm{mg}$ for those receiving the morphine solution versus $8.00 \mathrm{mg}$ for those receiving placebo. These results support an earlier study of the effects of epidural morphine on ventilation, submitted for publication elsewhere.

Studies of Factors Modifying the Inspiratory Carbon Dioxide Curve in the Bain Circuit. George Havasi, Ilona Havasi, Jonas Gintautas and Gabor B. Racz. Department of Anesthesiology, Texas Tech University, School of Medicine, P.O. Box 2217, Lubbock. Texas 79408 U.S.A.

The fresh gas flow requirement in the Bain circuit to maintain normocarbia with controlled ventilation is generally accepted to be about $70 \mathrm{ml} \cdot \mathrm{kg}^{-1} \cdot \min ^{-1}$ for healthy adult patients. Unfortunately, there is no general agreement on the rate of fresh gas flow which prevents hypercarbia in the spontaneously breathing patient. This prompted us to study the effectiveness of the circuit in a lung model and in consenting conscious volunteeers and anaesthetized patients.

Methods: We used an artificial lung model with $200 \mathrm{ml} / \mathrm{min}$ of carbon dioxide representing the minute production of the gas. Instantaneous carbon dioxide concentrations were monitored at the end of the tracheal tube both by a mass spectrometer, and a capnograph. High speed recordings were made in the presence of different fresh gas flow rates. tidal volumes. respiratory frequencies, inspiratory/expiratory time ratios and compliances using five different ventilators while a pneumotachograph was monitoring gas flows simultaneously. Similar respiratory settings were used with a mechanical device simulating a spontaneously breathing patient. In conscious volunteers tidal volumes, respiratory flow rates and carbon dioxide concentrations were monitored simultaneously in the presence of different gas flow rates. Similar measurements were done in ventilated or spontaneously breathing anaesthetized patients with fresh gas flow rates recommended in the literature.

Results: In over 1000 recordings we found the existence of typical, reproducible and depictable inspiratory carbon dioxide concentration curve. This curve has four phases. With controlled ventilation the lowest inspiratory concentration of carbon dioxide is reached at the end of the first phase. This concentration can be reduced by high fresh gas flow, low tidal volume, low respiratory frequency, low (1:3) inspiratory/expiratory time ratio, and poor compliance. During the second phase the concentration rises until it reaches the third or plateau phase. This plateau concentration can be reduced by high fresh gas flow, low respiratory frequency, low tidal volume, high $(1: 1)$ inspiratoryl expiratory time ratio, and poor compliance. During the fourth phase the curve decreases a little in the presence of low fresh gas flow, large tidal volume, and poor compliance. The best end-tidal carbon dioxide concentration was reached with any respiratory settings in the presence of this typical inspiratory carbon dioxide concentration curve. However, this curve was disadvantageously modified by ventilators providing endinspiratory hold and by the inspiratory flow rate pattern of spontaneous respiration. With these two factors the lowest inspiratory concentration of carbon dioxide was reached at the end of the inspiratory cycle. 
Discussion: The inspiratory carbon dioxide concentration curve helps to understand and to describe the precise mechanism of rebreathing in the Bain circuit. This curve, with the knowledge of gas flow rates in the inner and outer tubes of the circuit, explains why we need different fresh gas flow rates for controlled and spontaneous ventilation and why spontaneously breathing patients do not respond uniformly to any fresh gas flow rate.

Rebreathing and End-tidal Carbon Dioxide During Spontaneous Breathing with the Bain Breathing System. W.E. Spoerel. Department of Anaesthesia, University Hospital, 339 Windermere Road, London, Ontario N6A 5A5.

With the Bain breathing system (as a Mapleson D system) it is assumed that an increase in inspired carbon dioxide $\left(\mathrm{Fl}_{\mathrm{CO}_{2}}\right)$, as an indication of rebreathing, represents a carbon dioxide load which causes hyperpnoea as a compensatory response; a failure of this response due to anaesthetic depression of respiration would lead to hypercapnia. However, in controlled ventilation it could be shown that the $\mathrm{FI}_{\mathrm{CO}_{3}}$ changed independent of the end-tidal carbon dioxide ( $\mathrm{FET}_{\mathrm{CO}_{2}}$ ) in response to manipulation of volume and frequency of ventilation.

To examine the relationship between $\mathrm{FET}_{\mathrm{CO}_{2}}$ and $\mathrm{Fl}_{\mathrm{CO}_{2}}$ in spontaneously breathing patients under anaesthesia with a fresh gas volume of $100 \mathrm{ml} \cdot \mathrm{kg}^{-1} \cdot \mathrm{min}^{-1}$, the respiratory rate was changed in two groups of six patients each by the induction and reversal of narcotic depression. $\mathrm{FET}_{\mathrm{CO}_{2}}$ and $\mathrm{FI}_{\mathrm{CO}_{2}}$ were determined from a sampling catheter at the tip of the tracheal tube and gas samples were taken at intervals along the breathing tube and at the venting valve and analyzed with a mass spectrometer. Expiratory minute volume was measured with a Wright respirometer.

In light halothane anaesthesia, the intravenous injection of 6 to $9 \mathrm{mg}$ alphaprodine caused a fall in $\mathrm{Fi}_{\mathrm{CO}_{2}}$ from $2.3 \pm 0.5$ per cent to $0.7 \pm 0.17$ per cent concomitant with a reduction in respiratory rate from $37 \pm 5$ to $16 \pm 4$ breaths per minute. The mean tidal volume of $3.6 \mathrm{ml}$ $\mathrm{kg}^{-1} \cdot \min ^{-1}$ remained unchanged while the $\mathrm{FET}_{\mathrm{CO}_{2}}$ rose from $5.0 \pm 0.6$ per cent to $6.4 \pm 0.9$ per cent gradually over a 10 minute period. In anaesthesia with nitrous oxide and oxygen supplemented by alphaprodine, naloxone $0.1 \mathrm{mg}$ caused a rise in $\mathrm{FI}_{\mathrm{CO}_{2}}$ from $0.5 \pm 0.2 \mathrm{per}$ cent to $3.3 \pm 0.4$ per cent simultaneously with the rise in respiratory rate from 10 to 20 breaths per minute while the $\mathrm{FET}_{\mathrm{CO}_{2}}$ declined gradually from 8.3 to 6.9 per cent. The degree of mixing of inspired and expired gases within the breathing tube correlated with changes in respiration. In all cases the $\mathrm{FET}_{\mathrm{CO}_{2}}$ changed slowly in a direction opposite to the change in $\mathrm{FI}_{\mathrm{CO}_{2}}$.

With narcotic depression of respiration and its reversal, the $\mathrm{FI}_{\mathrm{CO}_{2}}$ can not be the cause, but must be the consequence of changes in breathing pattern; under this condition the volume of re-inhaled carbon dioxide changes passively and can not be regarded as a carbon dioxide load. As in controlled respiration, there was no indication during spontaneous breathing that the distribution of carbon dioxide within the Bain system reflected on either the $\mathrm{FET}_{\mathrm{CO}_{2}}$ or the elimination of carbon dioxide.
Ventilatory Responses to Induced Hypotension During Halothane Anaesthesia in Man. I.W.C. White, R.L. Knill and G. Varkey. Department of Anaesthesia, University Hospital, London, Ontario N6A 5A5

Conventional thinking on induced hypotension during anaesthesia with spontaneous ventilation is that there is a risk of alveolar hypoventilation due to either a central depression of ventilation or increase of the VD/VT ratio, or both. Accordingly, we studied the ventilatory responses to hypotension induced with sodium nitroprusside (SNP) in seven subjects who were about to undergo clipping of a vertebro-basilar artery aneurynsm (Grade I), but who were otherwise fit.

The patients were anaesthetized to steady states with nitrous oxide and halothane in concentrations sufficient to produce end-tidal levels equivalent to a total of 1-1.2 MAC. All patients breathed spontaneously throughout. Systemic arterial pressures were measured from an indwelling arterial cannula in either the dorsalis pedis or radial artery, and a calibrated pressure transducer (Ayltech. MG $10 \mathrm{~V}$ ).

After taking control readings, hypotension was induced with SNP ( 0.01 per cent) at a rate to maintain mean arterial pressure (head level) at approximately 50 per cent of control values. After 10 minutes of stable hypotension, and during a period of no surgical stimulation, we recorded ventilation and end-tidal concentrations of carbon dioxide, oxygen and halothane for a one minute period. Arterial blood was drawn for blood gas analysis.

Hypotension increased overall $V_{I}$ while reducing $\mathrm{Pa}_{\mathrm{CO}_{2}}$ values. There was a tendency for those subjects who experienced the greatest drop in arterial pressure to have the greatest increment of ventilation. All patients recovered without sequelae related to their anaesthetic procedure.

This preliminary data suggest that SNP induced hypotension of moderate magnitude increases both total and alveolar ventilation. The precise stimulus to breathing is unclear but is unlikely to be hypoxia.

A possible advantage of permitting spontaneous ventilation with induced hypotension is the use of ventilation as a sign of the adequacy of meduallary blood flow. This is of particular value during procedures which may compromise the vertebro-basilar blood supply.

\begin{tabular}{lccc}
\multicolumn{1}{c}{ Results: } & & \\
\hline \hline & Resting & Hypotension & $\mathrm{p}$ Values \\
\hline $\overrightarrow{\mathrm{BP}}(\mathrm{mm} \mathrm{Hg})$ & $77 \pm 5$ & $39 \pm 5$ & 0.01 \\
$\mathrm{~V}_{1}(\mathrm{l} / \mathrm{min})$ & $7.23 \pm 0.06$ & $9.74 \pm 1.09$ & 0.05 \\
$\mathrm{~Pa}_{\mathrm{cO}}$ & $37 \pm 1.5$ & $35 \pm 1.1$ & 0.02 \\
\hline
\end{tabular}

All values are mean \pm S.E.M.

Lorazepam and Diazepam as Adjuncts to Epidural Anaesthesia for Caesarean Section. B.Y. Ong, B.G. Pickering, R.J. Palahniuk and M. Cumming, Department of Anaesthesia, Health Sciences Centre-General, 700 William Avenue. Winnipeg, Manitoba R3E 023.

Many patients undergoing Caesarean section are anxious and require some sedation after delivery of the infant. Are lorazepam or diazepam good sedatives for patients undergoing Caesarean section with regional anaesthesia? We compared these two agents in a randomized double-blind study in 42 consenting patients. 
No patient with a significant medical or obstetrical complication was included in the study.

After delivery of the infant, 22 patients received lorazepam $0.05 \mathrm{mg} \cdot \mathrm{kg}^{-1}$ intravenously (lorazepam patients) and 20 patients received diazepam $0.1 \mathrm{mg} \cdot \mathrm{kg}^{-1}$ intravenously (diazepam patients). The two groups were compared for level of anxiety, vital signs and side effects. There was no significant difference in age or weight between the two groups.

Numerous major side effects occurred after both lorazepam and diazepam administration (Table I). The symptoms of delirium were severe and included hallucination, confusion, agitation, restlessness, inappropriate weeping and repetitive hand movements. Although the patients did not remember having these symptoms, at least one patient was extremely unhappy about her experience. Two of the lorazepam patients were so restless that their movement interfered with the surgery. Three of the lorazepam patients became delirious only after they returned to the ward from the recovery room. One patient was sufficiently confused that she attempted to climb over the side rails of her bed.

After receiving the drug, 15 per cent of the diazepam patients and 32 per cent of the lorazepam patients were judged to be agitated.

The respiratory rate, heart rate and mean blood pressure did not change significantly after drug administration in either group.

Patients in both groups experienced significant impairment of memory with over 90 per cent of the lorazepam patients having some amnesia for the perioperative period.

In this study, sedation with both lorazepam and diazepam were unsatisfactory. Some patients were more agitated after receiving these agents. Half (11/22) of the patients who received lorazepam had either symptoms of delirium or side effects that were bothersome enough to cause them to complain the following day. Also, delirium occurred some hours after discharge from recovery room in several patients. This is of particular concern because the patients on the ward are usually not observed continuously.

In conclusion, diazepam was not a satisfactory sedative for patients having Caesarean section while lorazepam at a dose of $0.05 \mathrm{mg} \cdot \mathrm{kg}^{-1}$ produced frequent undersirable side effects.

TABLE I

Percentage of Patients who Experience Side Effects

\begin{tabular}{lccc}
\hline & $\begin{array}{c}\text { Pain at } \\
\text { Injection Site }\end{array}$ & $\begin{array}{c}\text { Delirium } \\
\text { Symptoms* }\end{array}$ & $\begin{array}{c}\text { Failure to Recall } \\
\text { Piclure(s) Shown* }\end{array}$ \\
\hline $\begin{array}{c}\text { Lorazepam } \\
\text { Patients }\end{array}$ & $0 \%$ & $36 \%$ & $91 \%$ \\
$\begin{array}{l}\text { Diazepam } \\
\text { Patients }\end{array}$ & $35 \%$ & $10 \%$ & $50 \%$ \\
\hline$p<0.05$ by chi-square analysis. &
\end{tabular}

Three Per Cent 2-Chloroprocaine for Caesarean Section: Appraisal of a Standardized Dose Technique. W.D.R. Writer, D.M. Dewan and F.M. James III. Department of Anaesthesia, Victoria General Hospital, Halifax, Nova Scotia, B3H 2 Y9.

Epidural anaesthesia with 2-chloroprocaine produces greater maternal hypotension than bupivacaine, but offer's rapid onset of analgesia in Caesarean section. We found some patients to require more than the $20 \mathrm{ml}$ of 3 per cent, recommended by James, et al. A safe procedure must allow time to exclude accidental intrathecal or intravascular administration. We have evaluated a technique fulfilling these criteria which uses a minimum of $25 \mathrm{ml}$.

Methods: We studied 44 parturients having elective Caesarean section. The Clinical Research Practices Committee approved the protocol and all parturients gave informed consent. After establishing a 16 gauge intravenous cannula, we recorded baseline pulse and blood pressure (Riva-Rocci method) and infused one litre of balanced salt solution. Lumbar epidural block was done on recumbent subjects in the left lateral position and an epidural cannula was inserted. Mothers then received an "intrathecal" test dose of $2 \mathrm{ml}$ through the cannula. Five minutes later we asked them to move both legs and report any diffuse numbness. In the absence of change we administered 3 per cent chloroprocaine $8 \mathrm{ml}$ slowly, questioning about symptoms of intravascular injection. Parturients then assumed the left tilt position, wedged beneath the right hip. We continued rapid electrolyte infusion and recorded cardiovascular parameters every two minutes, giving intravenous ephedrine $100 \mathrm{mg}$ for abrupt or sustained hypotension not responding to fluid or increased tilt. Ten minutes after the "intravascular" test dose we noted the upper analgesia level, then gave a "therapeutic" dose of chloroprocaine $15 \mathrm{ml}$. Ten minutes later we recorded anaesthetic level, requiring numbness at T5 or ahove surgery, and gave $5 \mathrm{ml}$ increment(s), if needed, to achieve this. During operation mothers received chloroprocaine $10 \mathrm{ml}$ every 40 minutes. We graded analgesia with a pain relief score three times during operation. Neonatal status was assessed by Apgar scores and cord blood gases. Recovery time of motor and sensory function was noted.

Results: Thirity-seven subjects ( 84 per cent) had excellent analgesia; three ( 7 per cent) obtained good relief. Pain occurred most frequently between delivery and parietal closure. Four mothers required supplementary nitrous oxide analgesia. Twenty-seven parturients (61 per cent) attained T5 with chloroprocaine $25 \mathrm{ml}$; eleven ( 25 per cent) required $30 \mathrm{ml}$. Mothers over 35 years of age, or having a BMI (body mass index) 35 , developed higher segmental levels of analgesia. Upward drift $(3.8 \pm 1.7$ segments) followed the therapeutic dose but not the later $10 \mathrm{ml}$ doses. Motor $(64 \pm 21$ minutes) and sensory (68 \pm 20 minutes) function returned rapidly. Hypotension (MAP 80 per cent control) occurred in 24 parturients. An infused volume of $30 \mathrm{ml} / \mathrm{kg}$ at delivery significantly reduced post-delivery hypotension. Neonates from hypotensive mothers demonstrated significantly lower bicarbonate values $(\mathrm{P}<0.05)$

Sodium Citrate Premedication in the Parturient. D.M. Dewan, D.R. Writer, A.S. Wheeler, F.M. James III, H.M. Floyd. T.D. Bogard and A.L. Rhyne. Bowman Gray School of Medicine, 300 Hawthorne Road, Winston-Salem, North Carolina 27103 U.S.A.

Aspiration of gastric contents remains a leading cause of maternal morbidity and mortality associated with general anaesthesia. Laboratory work indicates that aspiration of more than $0.4 \mathrm{mg} \cdot \mathrm{kg}^{-1}$ of substance 
with a $\mathrm{pH}$ less than 2.5 is likely to cause sequellae. The prophylactic use of antacids has been advocated, but recent work indicates that aspiration of particulate antacids can also produce pulmonary injury. Sodium citrate, a clear antacid, has been proposed as an alternative to particulate antacids, but early work has been conflicting. We therefore decided to compare the efficacy of sodium citrate and Gelusil ${ }^{*}$ when used in the parturient.

Method: Forty-three healthy parturients with uncomplicated term pregnancies schedule for elective caesarean section under general anaesthesia were included in the study. Twenty patients received $30 \mathrm{ml}$ of Gelusil by mouth an estimated sixty minutes preoperatively. Thirteen additional patients received $30 \mathrm{ml}$ of sodium citrate - anise water (1:1) as their antacid. Anaesthesia was induced with intravenous thiopentone $3 \mathrm{mg} \cdot \mathrm{kg}^{-1}$ and the trachea was intubated following an intravenous bolus of succinylcholine $1.2 \mathrm{mg} \cdot \mathrm{kg}^{-1}$. Anaesthesia was then maintained with nitrous oxide and oxygen (2:1) using a 0.1 per cent succinylcholine infusion to provide muscle relaxation. Following trach eal intubation a number 18 Salem sump tube was passed orally and the stomach was emptied as completely as possible. The volume of each gastric specimen was measured and the $\mathrm{pH}$ analyzed using a Fischer Acumet $\mathrm{pH}$ meter. The results were then compared using the Students " $t$ " test and the Fischer exact test.

Results: The patient groups were similar in age, weight, and interval between antacid administration and sampling (Table I). The gastric volumes were similar; however, mean $\mathrm{pH}$ was lower in the sodium citrate group $(\mathrm{P}<0.05)$. The incidence of gastric $\mathrm{pH}$ values less than 2.5 was higher in the sodium citrate group $(\mathrm{P}<0.05)$ (Table 1). The lower gastric $\mathrm{pH}$ values in the Gelusil ${ }^{\text {t) }}$ group appeared to be related to longer intervals between drug administration and sampling. When sodium citrate was used this relationship was not apparent.

Conclusions: We conclude that, in the dose used in this study, sodium citrate is not a satisfactory alternate to Gelusil ${ }^{*}$ for increasing gastric $\mathrm{pH}$ in the parturient when given sixty minutes preoperatively.

\begin{tabular}{|c|c|c|}
\hline & Gelusil' $^{\mathfrak{E}}$ & Sodium Citrate \\
\hline Age (year) & $24.65 \pm 5.06$ & $27.07 \pm 5.89$ \\
\hline Weight (kg) & $75.75 \pm 30.57$ & $84.23 \pm 15.92$ \\
\hline Interval (min) & $84.45 \pm 17$ & $81.0 \pm 17.1$ \\
\hline Volume (ml) & $36.55 \pm 22$ & $34.39 \pm 16.1$ \\
\hline $\mathrm{pH}$ & $4.55 \pm 2.46$ & $2.29 \pm 1.77^{*}$ \\
\hline $\mathrm{pH}<2.5$ & $7 / 20(35 \%)$ & $11 / 13(84.6 \%)^{*}$ \\
\hline
\end{tabular}

Maternal and Neonatal B-Endorphin and Neonatal Outcome of Caesarean Delivery. D.W Coombs, J.G. Porter, C. Cate, M. Pageau and T.J. Webber. Department of Anesthesiology, Dartmouth-Hitchcock Medical Center, Hanover, New Hampshire 03755 U.S.A.

$\beta$-endorphin which emanates from maternal, foetal and placental sources, has been shown to increase near term gestation. Since $\beta$-endorphin may cause respiratory depression and altered states of consciousness, exposure of the foetus to elevated $\beta$-endorphin levels may make the foetus either analgesic during labour or, perhaps, result in respiratory depression. To investigate this possibility, we studied sixteen uncomplicated parturients during repeat elective caesarean delivery under lumbar epidural anaesthesia with bupivacaine 0.75 per cent $(18-22 \mathrm{ml})$ to obtain baseline data in neonates unstressed by labour. This investigation was approved by the institution's Committee for Protection of Human Subjects and all prospective mothers gave written informed consent.

Maternal plasma (M) and umbilical arterial (UA) and venous (UV) plasma were obtained simultaneously upon caesarean delivery and immediately placed in ice. Concomitantly umbilical arterial and venous blood were obtained for measurement of blood gases. One, five, and ten minute Apgar scores were also recorded. $\beta$-endorphin was measured by RIA (modified from Orth) after previous extraction and separation of BLPH with normal range of plasma $\beta$-endorphin being less than or equal to $150 \mu \mathrm{g} / \mathrm{ml}$.

Results: Normal $\beta$-endorphin levels were exceeded twofold by maternal and foetal umbilical levels (means were M-295.8 pg/ml, U.V. $-324.3 \mathrm{pg} / \mathrm{ml}$, and UA-363.7 $\mathrm{pg} / \mathrm{ml}$ ). No foetal respiratory depression was noted (Apgar scores 8 at all times). No evidence of foetal acidosis was detected.

Effect of Intravenous Diazepam on Rise of Intra-ocular Pressure After Succinylcholine. Anthony J. Cunningham, Odette Albert, A.G. Watson and J. Cameron. Department of Anaesthesia, Ottawa Health Science Centre, General Hospital, Ottawa, Ontario.

Published studies, from as early as 1955, have shown that succinylcholine, given intravenously to facilitate intubation, produces a transient but significant rise in intra-ocular pressure. In 1979 Fahamy, et al. and Eisenberg, et al. separately reported the effect of pretreatment with intravenous diazepam $0.05 \mathrm{mg} \cdot \mathrm{kg}^{-1}$ in reducing succinylcholine induced myalgia, serum $\mathrm{K}^{+}$ increase and C.P.K. increase. Intravenous diazepam has been shown to decrease intra-ocular pressure and this study was undertaken to see if pretreatment with intravenous diazepam prevented succinylcholineinduced rise in intra-ocular pressure.

The subjects of this study were unpremedicated 18 40 year old male and female patients undergoing elective surgery. There were two treatment groups:

Group I. 10 patients induced with sodium thiopentone $3-5 \mathrm{mg} \cdot \mathrm{kg}^{-1}$ and succinylcholine $1 \mathrm{mg} \cdot \mathrm{kg}^{-1}$.

Group 2. 20 patients given diazepam $0.1 \mathrm{mg} \cdot \mathrm{kg}^{-1}$ intravenously five minutes before induction with thiopentone $3-5 \mathrm{mg} \cdot \mathrm{kg}^{-1}$ and succinylcholine 1 $\mathrm{mg} \cdot \mathrm{kg}^{-1}$.

Intra-ocular pressure was recorded using applanation tonometry on arrival in the operating room (control), after succinycholine, two and five minutes after tracheal intubation. In group II, intra-ocular pressure was also recorded five minutes after diazepam.

The results of study showed that intravenous diazepam $0.1 \mathrm{mg} \cdot \mathrm{kg}^{-1}$ reduced intra-ocular pressure significantly from control and the subsequent intra-ocular pressure values after succinylcholine and after tracheal intubation were significantly lower in the group treated with diazepam.

This study suggests that treatment with intravenous diazepam be used before administration of succinylcholine for patients presenting for open eye operations 
and cataract extractions. A follow-up study will be undertaken to see if the addition of d-tubocurare $0.06 \mathrm{mg} \cdot \mathrm{kg}^{-1}$ to diazepam pre-treatment produces a further reduction in intra-ocular pressure after succinylcholine.

Labetalol for Controlled Hypotension in Surgery for Intracranial Aneurysm. D.J. Carswell, G.P. Varkey and C.G. Drake. Department of Anaesthesia, University Hospital, 339 Windermere Road, London, Ontario N6A 5A5

The anaesthetic management of intracranial aneurysm surgery includes the pharmacological induction of controlled hypotension. Although sodium nitroprusside is the current drug of choice, problems associated with this drug include tachycardia, tachyphylaxis, rebound hypertension, and the possibility of cyanide toxicity. Labetalol, a combined alpha and beta adrenergic blocking agent, has been used successfully for the control of chronic hypertension and acute hypertensive crisis. Scott and others (Anaesthesia, 33: 145, 1978) have reported the synergistic effect of Labetalol combined with halothane for hypotensive anaesthesia. We asked the question: "Can Labetalol be successfully substituted for sodium nitroprusside in the anaesthetic management of intracranial aneurysm surgery, and would this avoid the problems related to sodium nitroprusside?"

Contraindications included age less than 12 years, asthma, heart block, heart failure, and insulin-dependent diabetes mellitus. Fourteen unpremedicated patients with Class I and Class II intracranial aneurysms underwent smooth induction of anaesthesia with the stepwise use of thipentone ( \pm fentanyl), oxygen, $\mathrm{ni}$ trous oxide. halothane, and succinylcholine ( \pm pancuronium). Twelve patients had ventilation controlled and two breathed spontaneously. Mannitol ( \pm furosemide) diuresis and spinal drainage of cerebral spinal fluid allowed for a "slack" brain. We monitored heart rate, electrocardiogram, direct arterial pressure at head level, arterial blood gases, airway pressure, and urinary output. Fluid infusion was kept to a minimum before clipping of the aneurysm. Hypotension was initiated by increasing the concentration of halothane, followed by the administration of Labetalol 0.1 per cent solution by infusion pump. Mean arterial blood pressure fell to a level of $40-50 \mathrm{~mm} \mathrm{Hg}$ as required. The hypotensive effects of Labetalol and halothane were cautiously balanced to avoid extreme duration of action. When the aneurysm was clipped, Labetalol was gradually withdrawn and halothane was reduced. At the same time, replacement of fluid and blood loss were begun as indicated.

This technique allowed smooth induction of hypotension, giving good operating conditions in all cases without difficulty. Inspired halothane concentration averaged 1.5 per cent (range $0.725-2.5$ per cent). The average dose of Labetalol was $47 \mathrm{mg}$ (range $10-100 \mathrm{mg}$ ). Careful titration of these combined agents allowed judicious potentiation of their hypotensive effects. Mean arterial blood pressure was lowered to the range of $40-50 \mathrm{mmHg}$ for a duration of $10-70$ minutes. The heart rate decreased by an average of 13 per cent. Withdrawal of Labetalol and reduction of halothane caused the blood pressure to return to control values in an average of 11 minutes and no rebound hypertension was observed. We saw no cardiac dysrhythmias, no bronchospasm, and no adverse effects on arterial blood gas values. No postoperative morbidity or mortality was attributed to anaesthesia or to the hypotensive technique.

We conclude that Labetalol can be successfully used as an alternative to sodium nitroprusside in augmenting halothane for the hypotensive anaesthetic management of intracranial aneurysm surgery. Advantages appear to be the readily controlled hypotension and the avoidance of tachycardia, tachyphylaxis, and rebound hypertension.

Curare Increases Upper Airway Resistance While Reducing Ventilatory Muscle Strength. Bruce G. Dodgson, R.L. Knill and J.L. Clement. Department of Anaesthesia, University Hospital, London, Ontario NGA SAS.

Although the effects of curare on ventilatory volumes and ventilatory muscle strength are reasonably well defined, little is known of potential effects of the respiratory muscle concerned with maintaining patency of the upper airway. This study was undertaken to determine the effects of d-tubocurarine on upper airway resistance in healthy conscious supine volunteers.

A specially designed naso-oesophageal tube was positioned fluoroscopically so that two or three pressure measuring ports were situated at the level of the hypopharynx just above the glottic opening. With the subject breathing quietly through a mouthpiece attached to a pneumotachograph head, inspiratory flow rate versus pressure difference between the mouthpiece and the hypopharynx was plotted on an $X-Y$ recorder. Upper airway resistance (Ruaw) was calculated at an inspiratory flow rate of $30 \mathrm{l} / \mathrm{min}$. We also measured maximum inspiratory pressure (Insp.P max) maximum expiratory pressure (Exp.P max) and vital capacity (V.C.)

D-Turocurarine $(\mathrm{dTc})$ was administered intravenously in $3 \mathrm{mg}$ increments every five minutes until hand grip strength was nearly abolished. At each level of paralysis - maintained constant with respect to hand grip with a slow infusion of dilute dTc $(1-2 \mathrm{mg} / 100 \mathrm{ml})-$ the measurements were repeated.

With hand grip strength reduced to near 10 per cent of control. maximum inspiratory and expiratory pressures decreased slightly, but upper airway resistance more than doubled. Three of four subjects reported a sensa-

TABLE I

\begin{tabular}{|c|c|c|c|c|}
\hline \multirow[b]{2}{*}{ Results } & \multirow[b]{2}{*}{ Control } & \multicolumn{2}{|c|}{$\begin{array}{l}\text { dTc Dose } \\
\text { (Cumulative) }\end{array}$} & \multirow[b]{2}{*}{$12 \mathrm{mg}$} \\
\hline & & $6 \mathrm{mg}$ & $9 \mathrm{mg}$ & \\
\hline Hand Grip (kg) & $40 \pm 7$ & $30 \pm 3$ & $13 \pm 4$ & $5 \pm 3^{*}$ \\
\hline V.C. (L) & $4.78 \pm 0.44$ & - & $4.39 \pm 0.43$ & $4.07 \pm 0.42$ \\
\hline $\begin{array}{r}\text { Insp. } P \max \\
\left(\mathrm{cm} \mathrm{H}_{2} \mathrm{O}\right)\end{array}$ & $74 \pm 5$ & - & $72 \pm 4$ & $54 \pm 9^{*}$ \\
\hline $\begin{array}{r}\text { Exp. } P \max \\
\left(\mathrm{cm} \mathrm{H_{2 }} \mathrm{O}\right)\end{array}$ & $67 \pm 5$ & - & $52 \pm 7$ & $45 \pm 5^{*}$ \\
\hline $\begin{array}{l}\text { Ruaw } \\
\qquad\left(\mathrm{cm} \mathrm{H} \mathrm{H}_{2} \mathrm{O} / \mathrm{L} / \mathrm{sec}\right)\end{array}$ & $0.48 \pm 0.09$ & $0.5 \pm 0.15$ & $0.69 \pm 0.18$ & $1.04 \pm 0.03^{*}$ \\
\hline$n=4$ & & & & \\
\hline
\end{tabular}

All values are mean \pm S.E.M.

* Significantly different from control $(p=$ or $<0.05)$ 
tion of "heaviness" of the jaw and/or dysarthria. One subject with a near normal vital capacity attempted to sustain an augmented level of ventilation, but failed because of stridor and obvious upper airway obstruction.

We conclude that in addition to reducing ventilatory muscle strength, partially paralyzing doses of curare increase upper airway resistance. This presumably represents an action of curare on the tongue and/or pharyngeal muscles.

Effect of Enflurane and Fentanyl on Clinical Characteristics of Long-term Neuromuscular Block With Succinylcholine. François Donati. Department of Anaesthesia, Royal Victoria Hospital, 687 Pine Avenue West, Montreal, Quebec.

Non-depolarizing relaxants are potentiated by inhalational agents, particularly enflurane. However, the effect of inhalational agents on the block of long-term succinylcholinc is uncertain. This study compares the effect of enflurane and fentanyl on the characteristics of the depolarizing and phase II block produced by prolonged succinylcholine infusions.

Forty adult patients, ASA Class I or 1I, scheduled for elective general surgery of an expected duration of one to four hours, were induced with thipentone 3-5 $\mathrm{mg} \cdot \mathrm{kg}^{-1}$. Anaesthesia was maintained with either 1-2 per cent enflurane or fentanyl $0.25 \mathrm{mg}$ intravenously followed by $0.1 \mathrm{mg}$ every 20 minutes. Twenty patients were assigned randomly to each group. The ulnar nerve was stimulated at the wrist and force of contraction of the adductor pollicis muscle was recorded. Train-offour stimuli ( $2 \mathrm{~Hz}$ every 10 seconds) were applied. A succinylcholine infusion was started at a rate sufficient to provide adequate conditions for tracheal intubation within 1-2 minutes, and then was adjusted to maintain the force of contraction of the first of four twitches at $10-15$ per cent of the preinfusion value. Cumulative doses ranged from 1.53 to $20.23 \mathrm{mg} \cdot \mathrm{kg}^{-1}$. The neuromuscular junction was allowed to recover for 10 minutes after the infusion was stopped. Patients with a fourth to first twitch ratio of less than 50 per cent received atropine $1.2 \mathrm{mg}$ and neostigmine $2.5 \mathrm{mg}$.

Initially, all patients exhibited a depolarizing-type block, all twitches of the train-of-four being roughly the same size. The infusion rate was similar in the enflurane $\left(0.057 \mathrm{mg} \cdot \mathrm{kg}^{-1} \cdot \mathrm{min}^{-1}\right)$ and the fentanyl $(0.066 \mathrm{mg}$. $\mathrm{kg}^{-1} \cdot \min ^{-1}$ ) groups. Tachyphylaxis was present in both groups and correlated well with the onset of phase II block (dual block). This occurred sooner and at a lower cumulative dose in the enflurane group. Fourth to first twitch ratios decreased to 50 per cent, 25 per cent, and 0 per cent in 32, 45 and 57 minutes in the enflurane group, at cumulative succinylcholine doses of $2.25,3.1$ and $4.4 \mathrm{mg} \cdot \mathrm{kg}^{-1}$ respectively. Corresponding figures for the fentanyl group were 57,78 and 93 minutes, with doses of $3.3,5.5$ and $6.3 \mathrm{mg} \cdot \mathrm{kg}^{-1}$. Infusion rates increased markedly after establishment of dual block, but were similar with enflurane $\left(0.99 \mathrm{mg} \cdot \mathrm{kg}^{-1} \cdot \mathrm{min}^{-1}\right)$ and fentanyl $\left(1.12 \mathrm{mg} \cdot \mathrm{kg}^{-1} \cdot \mathrm{min}^{-1}\right)$. Spontaneous recovery (fourth twitch more than half the first) failed to occur in most patients given enflurane who received more than $6 \mathrm{mg} \cdot \mathrm{kg}^{-1}$ succinylcholine over more than 90 minutes. Corresponding figures for fentanyl patients were $10 \mathrm{mg} \cdot \mathrm{kg}^{-1}$ and 150 minutes. All 15 patients $(9$ enflurane, 6 fentanyl) who did not recover spontan- eously were successfully reversed with atropine and neostigmine.

In contrast to tubocurarine and pancuronium this study showed that succinylcholine requirements are not reduced significantly by enflurane. In addition, tachyphylaxis resulted in increased infusion rates by about 80 per cent in both enflurane and fentanyl anaesthesia. However, enflurane was associated with an earlier onset of tachyphylaxis and dual block, and full reversal was more likely to require anticholinesterases.

Naloxone and Halothane Anaesthesia: Opiate Antagonist or Non-Specific Analeptic. G. Dyke and H. Manson. Department of Anaesthesia, Memorial University of Newfoundland, St. John's, Nfld.

Recent research has suggested that the production of analgesia by nitrous oxide' and possibly by other anaesthetic agents ${ }^{2}$ may be related to the release of endorphins. These conclusions are reached indirectly by the assumption that naloxone acts only as a specific narcotic antagonist and does not have a non-specific analeptic effect.

Earlier work in our laboratory indicated that naloxone reversed other effects of halothane anaesthesia such as respiratory depression. ${ }^{3}$ Significant increases in tidal volume and reduction in respiratory rate were produced when naloxone $10 \mathrm{mg} \cdot \mathrm{kg}^{-1}$ was administered to rats anaesthetized with 1.5 per cent halothane. These results have been confirmed in a larger blinded series.

In order to delineate whether these effects are produced by antagonism of endorphins or by a non-specific analeptic effect we have looked for evidence of respiratory stimulation in awake rats breathing air and exposed to the same dose of naloxone.

Again, total body plethysmography was used and the rats were exposed in a blinded fashion. These results were compared to those of the group exposed to halothane.

Both groups exposed to halothane showed significant depression of tidal volume 2-3 hours after induction ( $p$ $<0.01$ ). The group which was exposed to naloxone $10 \mathrm{mg} \cdot \mathrm{kg}^{-1}$ showed a return of tidal volume to predepression levels at one minute after injection and a lesser increase 5,10 and 15 minutes. The tidal volumes at 15 minutes after injection were significantly higher than these immediately before injection $(p<0.05)$.

There was no significant effect on tidal volume in the group who received an equal volume of saline during halothane anaesthesia. There was no significant effect on respiratory rate following naloxone or saline injection in the halothane group.

In the group breathing room air, there was no significant effect on respiratory rate or tidal volume following intravenous administration of naloxone $10 \mathrm{mg} \cdot \mathrm{kg}^{-1}$ or an equal volume of saline.

\section{REFERENCES}

1. Berkowitz, B.A., NGai, S.H. \& Finck, A.D. Nitrous Oxide Analgesia - Reversal by Naloxone and Development of Tolerance J. Pharmacol. Exp. Ther. 203: 539 (1977).

2. FinCK, A.D., Ngai, S.H. \& Berkowitz, B.A. Antagonism of General Anaesthesia by Naloxone in the Rat. Anesthesiology 46: 241-245 (1977). 
3. Dyke, G. \& Manson, H. (Preliminary Report) Naloxone Reverses Halothane Induced Respiratory Depression. Canadian Anaesthetists' Society Eastern Regional Meeting (1980).

Chemical Regulation of Ventilation During Isoflurane Sedation and Anaesthesia. H. Kieraszewicz, R.L. Knill and J.L. Clement. Department of Anaesthesia, University of Western Ontario, London, Ontario N6A 5A5

Enflurane and halothane depress, in a dose-related fashion, the central and peripheral chemoreceptormediated reflexers that determine ventilation and ventilatory responses to carbon dioxide and hypoxaemia. Isoflurane is being introduced into anaesthetic use in Canada and it is therefore important to determine the effects of this agent on chemical regulation of ventilation.

Fit subjects, ages 18 to 37 years, were studied while awake and in a steady state of either isoflurane sedation 0.1 MAC (n-5), or isoflurane anaesthesia 1.1 MAC (n-7). No other drugs were administered. The variables measured were ventilation, $\mathrm{PET}_{\mathrm{CO}_{2}}$ and the ventilatory responses to $(\mathrm{A})$ hyperoxic hypercarbia $\left(\mathrm{PCO}_{2}\right.$ increment 10-20 torr), (B) isocapnic hypoxaemia (to $\mathrm{PET}_{\mathrm{O}_{2}}$ 40-50 torr), and (C) a single breath of carbon dioxide in oxygen which in the sedation group was a vital capacity of 13 per cent carbon dioxide in oxygen and in the anaesthesia group a 0.5 vital capacity of 20 per cent carbon dioxide in oxygen. (A) is primarily a central chemoreceptor mediated response; (B) and (C) are peripheral chemoreceptor-mediated. Conventional carbon dioxide responses were expressed as the slope of the linear $\dot{\mathrm{V}}_{1}: \mathrm{PCO}_{2}$ relationship, hypoxaemic responses as the shape parameter " $\mathrm{A}$ " of the hyperbolic $\mathrm{V}: \mathrm{PO}_{2}$ relationship, and single breath carbon dioxide responses as the increment of ventilation $\left(\Delta \dot{V}_{l}\right)$ within 12 seconds of the single breath stimulus.

Isoflurane sedation impaired only the ventilatory respone to hypoxaemia. Anaesthesia reduced the activity of all three reflexes, with relatively greater impact on the hypoxaemic and single breath carbon dioxide responses.

Isoflurane, like halothane and enflurane, selectively impairs ventilatory reflexes mediated by peripheral chemoreceptors

TABLE I

\begin{tabular}{|c|c|c|}
\hline \multirow[b]{2}{*}{ Results } & \multicolumn{2}{|c|}{ Isoflurane $0.1 \mathrm{MAC}(\mathrm{n}-5)$} \\
\hline & Awake & Sedation \\
\hline $\begin{array}{l}\dot{V}_{I}(1 / \min ) \\
\text { PET }_{\text {con }} \text { (torr) }\end{array}$ & $\begin{array}{r}7.9 \pm 0.4 \\
41 \pm 0.7\end{array}$ & $\begin{array}{r}7.7 \pm 0.7 \\
40 \pm 0.7\end{array}$ \\
\hline \multirow[t]{2}{*}{$\begin{array}{l}\text { Responses: } \\
\mathrm{CO}_{2}(1 / \mathrm{min} \text { torr) } \\
\text { Hypoxaemic "A" (1/torr/min) } \\
\text { S.B.CO, } \Delta \dot{\mathrm{V}} \mathrm{(1/ \textrm {min } )}\end{array}$} & $\begin{array}{c}2.0 \pm 0.4 \\
196 \pm 18 \\
20.2 \pm 2.7\end{array}$ & $\begin{array}{r}2.6 \pm 0.8 \\
81 \pm 23^{*} \\
17.6 \pm 1.8\end{array}$ \\
\hline & \multicolumn{2}{|c|}{ Isoflurane $1.1 \mathrm{MAC}(\mathrm{n}-7)$} \\
\hline Results & Awake & Sedation \\
\hline $\begin{array}{l}\dot{V_{I}}(1 / \min ) \\
\operatorname{PET}_{\mathrm{CO}} \text { (lorr) }\end{array}$ & $\begin{array}{r}6.7 \pm 0.6 \\
38 \pm 0.4\end{array}$ & $\begin{array}{r}4.8 \pm 0.4^{*} \\
44 \pm 2.8^{*}\end{array}$ \\
\hline $\begin{array}{l}\text { Responses: } \\
\mathrm{CO}_{2}(1 / \mathrm{min} \text { torr }) \\
\text { Hypoxaemic } \cdots A \cdots(1 / \text { torr/min }) \\
\text { S.B.CO } 2 \Delta \dot{V}_{1}(1 / \mathrm{min})\end{array}$ & $\begin{array}{l}1.8 \pm 0.2 \\
236 \pm 42 \\
8.4 \pm 1.7\end{array}$ & $\begin{array}{l}0.6 \pm 0.1^{*} \\
7.8 \pm 5.2^{*} \\
1.2 \pm 0.5^{*}\end{array}$ \\
\hline
\end{tabular}

Time Course of Hypoxaemia in Pulmonary Embolism. R. Martineau, J.C. Kay and W.H. Noble. Department of Anaesthesia, St. Michael's Hospital, 30 Bond Street, Toronto, Ontario.

To define the underlying mechanism of hypoxaemia after pulmonary embolism, we measured pulmonary haemodynamics, gas exchange, and lung water in dogs embolized with starch micro-emboli.

Mongrel dogs were anaesthetized with pentobarbitone. A tracheostomy was done, and all dogs breathed room air spontaneously. The femoral artery, pulmonary artery and left atrium were catheterized for pressure monitoring and blood sampling. Cardiac output and extravascular thermal volume of the lung (ETVL) were measured using a thermal dilution technique. Blood gases and concentrations of expired oxygen and carbon dioxide were measured. Venous admixture (Qs/QT) was calculated. After control measurements were recorded, $0.15 \mathrm{~g} \cdot \mathrm{kg}^{-1}$ of starch micro-emboli were injected into a jugular vein. If necessary an additional dose was given to obtain an initial mean pulmonary artery pressure $(\overline{P A})$ of 40 to $50 \mathrm{~mm} \mathrm{Hg}$. Measurements were repeated every 30 minutes. At the end of the experiment, the animals were killed and lung water was determined using a post mortem weighing technique. ETVL agreed well with post mortem measurements.

Immediately following embolization, $\mathrm{P} \overrightarrow{\mathrm{PA}}$ increased from $17 \pm 0.8$ to $37 \pm 6 \mathrm{~mm} \mathrm{Hg}$ and Qs/QT increased from $11 \pm 2$ to $40 \pm 7$ per cent, while ETVL changed minimally $\left(7.2 \pm 1.4\right.$ to $\left.8.9 \pm 1.8 \mathrm{ml}-\mathrm{kg}^{-1}\right)$. Later ETVL increased to $19.5 \pm 5 \mathrm{ml} \cdot \mathrm{kg}^{-1}$ and Qs/QT increased

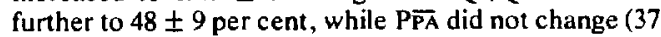
$\pm 2 \mathrm{~mm} \mathrm{Hg}$ ). The large increase in Qs/QT occurred immediately after embolization, before $E T V_{L}$ had increased.

We have previously shown that pulmonary hypertension occurring after pulmonary embolism diminishes the effect of hypoxic pulmonary vasoconstriction. This pulmonary hypertension increases perfusion to poorly ventilated areas, increases QS/QT, and causes hypoxaemia. However pulmonary oedema does occur in pulmonary embolism and this can also increase QS/QT and cause hypoxaemia.

We conclude that the hypoxaemia which is seen immediately following pulmonary embolism is not a result of pulmonary oedema, but is secondary to an increase in $\mathrm{Qs} / \mathrm{Qr}$ due to pulmonary hypertension. Later, as pulmonary oedema occurs, Qs/QT increases further and hypoxaemia becomes more severe.

Mechanisms of Barbiturate Protection Against Free Radical Damage of Model Membranes. Mary Jane Mitchell, David V. Godin and Brian Saunders. Department of Anaesthesiology, Faculty of Medicine, University of British Columbia, Vancouver, B.C.

Although iatrongenic barbiturate coma has led to new hope for protection of the brain against ischaemic and hypoxic injury, there is little understanding of the molecular mechanisms underlying either the injury or the proposed protection. Studies by Demopoulos and others have led to the hypothesis that under pathological conditions free radical reactions, which normally are controlled by natural scavengers, may accelerate and lead to the accumulation of highly reactive species, derived from molecular oxygen: namely, hydroxyl 
radicals (HO.), superoxide radicals $\left(\mathrm{O}_{\overline{2}}\right)$ and singlet oxygen $\left(\mathrm{O}_{2} \cdot\right)$. Under these conditions alterations in the structural and functional integrity of brain cellular and subcellular membrane systems would be expected to occur since oxidation-sensitive moieties are present both in proteins and in phospholipids, the two major chemical components of biological membranes. In theory, then, barbiturates or other agents protecting against brain ischaemic injury could exert their beneficial effects either by direct scavenging of reactive radicals or by preventing the consequences of their action at the cell membrane level.

The present study describes experiments to explore these two hypotheses, employing the human erythrocyte, the most commonly used and extensively characterized model membrane system. A variety of chemical and enzymatic systems were used to generate the oxygen radicals in question. The first system involved the peroxidation of fresh intact erythrocytes by hydrogen peroxide, which is known to produce the entire array of radicals mentioned above. Oxidative damage in the absence or presence of drugs was determined by assaying malondialdehyde (MDA), a by-product of lipid peroxidation. At equimolar drug concentrations ( $1 \mathrm{mM}$ ), the order of protection was: propranolol ( 70 per cent) sodium pentobarbitone (68 per cent), thiopentone (62 per cent) and sodium phentobarbitone ( 5 per cent). Mannitol, a known hydroxyl scavenger, protected approximately 40 per cent at a clinically relevant concentration $(0.1 \mathrm{M})$. The results indicate that barbiturates and mannitol protect the membranes against damage, but because the effects were strictly additive it seems unlikely that barbiturates act by scavenging hydroxyl radicals. In the second system, singlet oxygen was generated by photolysis in the presence of Rose
Bengal. Although singlet oxygen produced lipid peroxidation of isolated erythrocyte membranes, sodium pentobarbitone offered no detectable protection. The observations that Rose Bengal-sensitized photolysis of intact erythrocytes produced an increase in osmotic fragility enabled us to differentiate the ability of barbiturates to stabilize oxidatively-damaged cells by an action at the membrane level from direct free radical scavenging. Pentobarbitone, however, was devoid of any protective action under these conditions. Hence the ability of this barbiturate to protect membranes seems unrelated to singlet oxygen. Finally, the ability of barbiturates to interact directly with superoxide radicals produced enzymatically by the oxidation of xanthine by xanthine oxidase in a membrane-free system was investigated. The known superoxide scavenger superoxide dismutase inhibited the action of superoxide by 83 per cent. Sodium pentobarbitone in concentration previously shown to produce marked protection against hydrogen peroxide-induced peroxidation of erythrocytes was entirely ineffective, implying that any protection produced by barbiturates is probably unrelated to the superoxide radical.

The experiments to date indicate that the protective effects of barbiturates against brain ischaemic or hypoxic injury are unlikely to be due to reactive oxygen radical scavenging. The marked protective effect by propranolol and the minimal protection by phenobarbitone (the least lipid soluble of the barbiturates examined) in the hydrogen peroxide-erythrocyte model system suggest that membrane stabilization rather than direct radical seavenging may underlie this protective action, whose relevance to brain injury in vivo remains to be determined. 